\title{
STUDI EKSPERIMENTAL VIBRASI TORSIONAL DENGAN VARIASI PUTARAN PADA RODA GIGI LURUS
}

\author{
Purwatmo $^{1}$, Ikhwansyah Isranuri ${ }^{2}$, M. Sabri ${ }^{3}$, Syahrul Abda $^{4}$, Farida Ariani ${ }^{5}$ \\ 1,2,3,4,5 Departemen Teknik Mesin, Fakultas Teknik, Universitas Sumatera Utara \\ E-mail : purwatmoo@ymail.com
}

\begin{abstract}
Sejalan dengan perkembangan teknologi, pendeteksian getaran mesin dengan metode klasik yaitu interaksi antara manusia (operator) dan mesin dengan cara mendengarkan suara mesin dan menyentuh/meraba (hearing and touching) tidak lagi handal untuk dilakukan, karena mesin-mesin modern dirancang berjalan secara otomatis dan beroperasi pada putaran dan kecepatan tinggi. Untuk itu dibutuhkan peralatan uji ataupun peralatan pengukur sebagai bagian proses kegiatan Condition Based Maintenance (CBM). Penelusuran getaran yang terjadi pada mesin dapat berupa getaran translasi maupun rotasi. Penelitian ini bertujuan untuk menganalisa pengaruh variasi putaran terhadap getaran torsional. Instrumen eksperimental ini dilakukan dengan menggunakan Vibrometer laser ometron VQ-400-A-F. Roda gigi yang distudi adalah roda gigi lurus dengan jumlah gigi 36.

Hasil penelitian menunjukan bahwa nilai getaran torsional pada kecepatan $400 \mathrm{rpm}$ sebesar 0,000822726 kg.m.s dan getaran torsional pada putaran $1200 \mathrm{rpm}$ sebesar 0,000307676 kg.m.s, dapat disimpulkan bahwa semakin besar kecepatan putaran pada mesin maka semakin kecil getaran torsional yang dihasilkan.
\end{abstract}

Kata kunci: Roda gigi, Deteksi kerusakan, Vibration torsional, Predictive maintenance, Vibration monitoring.

\section{PENDAHULUAN}

Getaran torsional adalah gerakan sudut yang menimbulkan puntiran pada poros, gerakan osilasi ditumpangkan pada gerak rotasi stabil dari sebuah mesin yang berputar. Meskipun getaran ini tidak dapat diteksi dengan alat ukur khusus, amplitudonya dapat merusak. Sebagai contoh sepasang roda gigi yang mengubah kecepatan sistem transmisi daya mengirimkan ke casing. Demikian pula, mekanisme mesin silinder dalam suatu mesin kompresor mengkonversi torsi untuk kekuatan radial yang dapat dilihat oleh persepsi manusia tetapi tidak terukur karena ketidakpekaan alat uji dan latar belakang kebisingan. Jika gear box atau mesin torak adalah bagian dari drive train, kelebihan kebisingan dan getaran dapat menunjukkan masalah. Standar dan metode pengukuran yang berhubungan dengan besaran yang diterima getaran radial, gerak jarang menjadi perhatian dengan getaran torsional kecuali mempengaruhi fungsi sistem. Tekanan ini yang mempengaruhi integritas struktural dan umur komponen dengan demikian menentukan besarnya yang diijinkan getaran torsional. Gerakan getaran torsional dapat menghasilkan tegangan yang menyebabkan kelelahan logam. Selain itu, faktor konsentrasi tegangan diasosiasikan dengan komponen mesin untuk mengurangi efektivitas bahan beban [1].

Dari itu penulis melakukan penelitian untuk mengetahui pengaruh variasi putaran terhadap getaran torsional pada transmisi roda gigi lurus.

\section{TINJAUAN PUSTAKA}

\subsection{Karakteristik Getaran}

Getaran secara teknik didefenisikan sebagai gerak osilasi dari suatu objek terhadap posisi objek awal/diam. Kondisi getaran suatu mesin dan masalah-masalah mekanik yang terjadi dapat diketahui dengan mengukur karakteristik getaran yang timbul. Karakteristik utama getaran yaitu: 
1) Frekuensi merupakan karakteristik dasar pengukuran dan menggambarkan jumlah gerak osilasi tiap detik.

2) Perpindahan mengindikasikan berapa jauh suatu objek bergetar

3) Kecepatan mengindikasikan berapa cepat objek bergetar

4) Percepatan mengindikasikan suatu objek bergetar terkait dengan gaya penyebab getaran

\subsection{Gerak Harmonik}

Getaran dari sebuah mesin merupakan resultan dari sejumlah getaran individu komponen yang muncul. Setiap komponen individu yang bergetar memiliki gerak periodik. Gerakan akan berulang pada periode waktu pengulangan $(\tau)$ disebut perioda osilasi diukur dalam satuan detik dan kebalikannya adalah frekuensi dengan rumusan [2]:

$$
f=\frac{1}{\tau}
$$

Frekuensi lingkaran atau kecepatan sudut dapat dihitung dengan rumus:

$$
\omega=2 \pi \frac{1}{\tau}=2 \pi f
$$

Kecepatan sudut $(\omega)$ biasanya diukur dalam radian per detik (rps). Bentuk sederhana dari gerak periodik adalah gerak harmonik, pada gerak harmonik, hubungan antara perpindahan maksimum dan waktu dinyatakan dengan:

$$
x=A \sin \omega t
$$

Kecepatan dalam gerak harmonik berdasarkan persamaan (2.3) dapat diperoleh dari hasil diferensial perpindahan terhadap waktu, yaitu:

$$
\frac{d x}{d t}=\dot{x}=\omega A \cos \omega t
$$

Sedangkan percepatan harmonik diperoleh dari hasil diferensial kecepatan terhadap waktu:

$$
\frac{d^{2}}{d t^{2}}=\ddot{x}=-\omega^{2} A \sin \omega t
$$

Amplitudo melekat pada ketiga besaran perpindahan, kecepatan, dan percepatan.

\subsection{Getaran Torsional}

Penelusuran getaran yang terjadi pada mesin dapat berupa getaran translasi maupun rotasi. Getaran translasi dapat terjadi dalam arah lateral ataupun aksial. Getaran lateral terjadi pada arah tegak lurus sumbu poros, sedangkan getaran aksial terjadi dalam searah sumbu poros. Getaran rotasi merupakan getaran yang terjadi dalam arah putar sering disebut sebagai getaran torsional. Getaran torsional adalah getaran penyimpangan sudut periodik yang terjadi diakibatkan bekerjanya eksitasi gaya torsi (momen) pada poros elastis. Osilasi torsional pada poros berdasarkan perumusan sebagai berikut:

$$
\theta(t)=M \frac{L}{\operatorname{lp} G}
$$

Ekuivalen getaran linear dan torsional dapat dilihat pada Gambar 2.1.

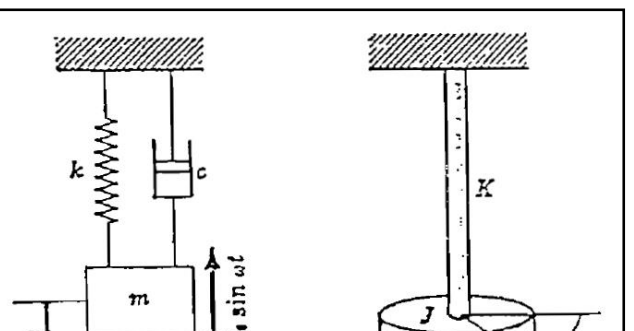


Gambar.2.1. Ekuivalen getaran linear dan torsional

\subsection{Roda Gigi lurus}

Roda gigi digunakan untuk mentransmisikan daya dan putaran yang tepat, sering digunakan karena dapat meneruskan putaran dan daya yang lebih bervariasi dan tepat daripada menggunakan alat transmisi yang lainnya, selain itu rodagigi juga memiliki beberapa kelebihan jika dibandingkan dengan alat transmisi lainnya, yaitu [3]:

- Sistem transmisinya lebih ringkas, putaran lebih tinggi dan daya yang besar.

- Sistem yang kompak sehingga konstruksinya sederhana.

- Kemampuan menerima beban lebih tinggi.

- Efisiensi pemindahan dayanya tinggi karena faktor terjadinya slip sangat kecil.

- Kecepatan transmisi rodagigi dapat ditentukan sehingga dapat digunakan dengan pengukuran yang kecil dan daya yang besar.

\section{METODOLOGI PENELITIAN}

\subsection{Tempat dan Waktu}

Penelitian ini dilaksanakan sejak tanggal 22 Mei 2014 pengesahan usulan oleh pengelola program studi sampai dinyatakan selesai yang direncanakan berlangsung selama \pm 4 bulan. Tempat pelaksanaan penelitian adalah di Research Center Noise/Vibration Control and Knowledge Based in Engineering, Program Magister Teknik Mesin, Fakultas Teknik, Universitas Sumatera Utara

\subsection{Peralatan Subjek Penelitian}

Subjek penelitian ini adalah pompa sentrifugal yang dipasang sesuai model instalasi sederhana skala laboratorium.

Tabel.3.1 Daftar spesifikasi perangkat penelitian

\begin{tabular}{|c|c|c|c|}
\hline No & Nama & Spesifikasi & Jumlah \\
\hline 1 & Meja & $\begin{array}{c}\text { Uk. } \\
500 \times 500 \times 500 .\end{array}$ & 1 unit \\
\hline 2 & Poros & $\varnothing 20 \times 300 \mathrm{~mm}$ & 1 buah \\
\hline 3 & Poros & $\varnothing 20 \times 500 \mathrm{~mm}$ & 1 buah \\
\hline 4 & $\begin{array}{l}\text { Pillow Block } \\
\text { bearing }\end{array}$ & $\begin{array}{c}\text { NTN, Tipe } \\
\text { P204 }\end{array}$ & 4 unit \\
\hline 5 & $\begin{array}{l}\text { Dudukan } \\
\text { pillow block } \\
\text { bearing }\end{array}$ & $\begin{array}{c}40 \times 100 \times 127 \\
\mathrm{~mm}\end{array}$ & 4 unit \\
\hline 6 & Spur gear & $\mathrm{Z}=33, \mathrm{M}=2,5$ & 2 buah \\
\hline 7 & V-Pulli & $\begin{array}{c}\varnothing 60 \mathrm{~mm}, \\
\text { Tipe-A }\end{array}$ & 2 buah \\
\hline 8 & V-belt & Mitsubosi, & $1 \mathrm{Buah}$ \\
\hline
\end{tabular}




\begin{tabular}{cccc}
\hline & & A39 & \\
& & LM-MOTOR, & \\
& Elektromotor & $1 \mathrm{Hp}(0,75 \mathrm{KW}), \quad 1$ unit \\
& & $1380 \mathrm{rpm}$ \\
& & & \\
10 & Inverter & $\begin{array}{c}\text { Sumitomo 1 } \\
\text { HP }\end{array}$ & 1 unit \\
\hline
\end{tabular}

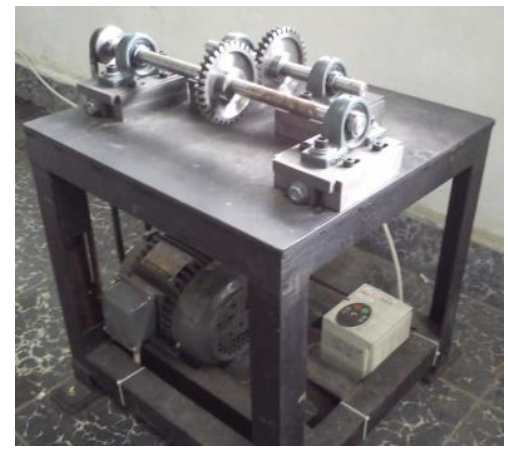

Gambar 3.1 kontruksi alat penelitian

A. Peralatan pengukuran

1. Vibrometer laser Ometron VQ-400-A-F untuk Mengukur getaran pada rodagigi.

2. Tachometer DT-2236 untuk Mengukur Rpm pada poros

3. Jangka Sorong dengan Akurasi 0,02 mm untuk Mengukur kesejajaran antar poros.

4. Labjack UE-9Pro untuk Mengubah sinyal getaran menjadi data digital

5. Laptop dengan dilengkapi software Matlab untuk Mengolah data digital.

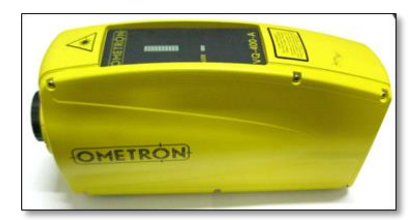

Gambar 3.2 Vibration meter Ometron VQ400AF

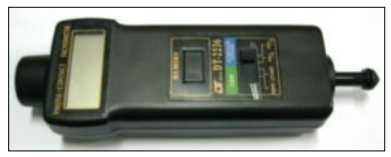

Gambar 3.3 Tachometer DT2236

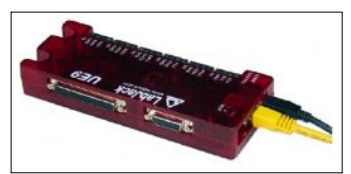

Gambar 3.4. Labjack UE-9 Pro 


\subsection{Metodologi}

Metode pengujian rencananya dilakukan yaitu pengujian langsung, dimana pada pengujian ini, seluruh variabel nilainya didapat dari hasil pengukuran dan digunakan bahan pengamatan atau analisis. Pada pengujian ini variabel yang digunakan terdiri dari sinyal getaran dan fenomena getaran.

Penyelidikan sinyal getaran yang timbul akibat variasi putaran, gaya-gaya yang di timbulkan roda gigi, dengan titik pengukuran searah Horizontal, Vertikal, dan Aksial dengan kecepatan 400rpm, 500rpm, 600rpm, 700rpm, 800rpm, 900rpm, 1100rpm dan 1200rpm. Pengukuran dilakukan pada titik yang telah ditentukan dengan pengambilan berdasarkan time domain, dimana titik berat pengukuran berada pada roda gigi.

Set up peralatan pengujian dilakukan untuk memperoleh data eksperimental sebagai berikut:

a. Hubungkan Vibrometer dengan power supplay dan labjack.

b. Hubungkan Labjack dengan Vibrometer dengan menggunakan probe analog.

c. Hubungkan labjack ke PC dengan mengunakan USB cable.

d. Pasang dan operasikan vibrometer dengan tegangan 12 Volt/1A yang arusnya diatur melaui power supplay.

e. Kondisikan jarak antara vibrometer dengan roda gigi dengan jarak $376 \mathrm{~mm}$.

f. Arahkan vibrometer laser kearah roda gigi kemudian arahkan lasernya pada posisi Horizontal, Vertikal, dan Aksial.

g. Hidupkan motor untuk mengerakkan roda gigi.

h. Pada arah Horizontal lakukan pengambilan data dengan kecepatan putaran yaitu 400rpm, 500rpm, 600rpm, 700rpm, 800rpm, 900rpm, 1000rpm, 1100rpm dan 1200rpm dengan menggunakan inverter. Lakukan hal yang sama pada arah Vertikal dan Aksial.

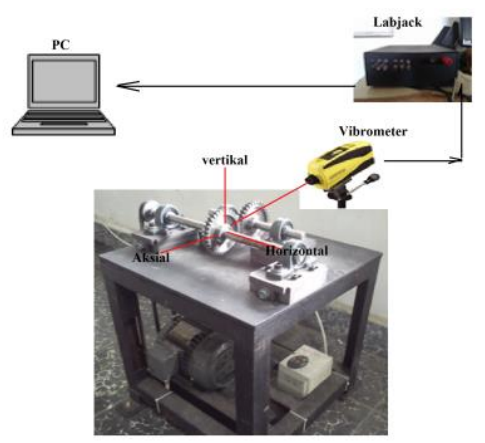

Gambar 3.5. Rangkaian analisa pengukuran data getaran

\subsection{Variabel Yang Diamati}

Sesuai dengan maksud penelitian, variable ini menjadi focus perhatian yang perlu dikondisikan untuk pengolahan data guna mendapatkan suatu hasil yang mendekati sempurna.

Adapun variabel yang diamati dalam penelitian ini adalah :

1. Pada saat pemasangan roda gigi, poros harus sejajar dan di ukur dengan jarak yang sama antara poros penggerak dengan poros yang digerakkan menggunakan vernier calliper.

2. Jarak Vibrometer laser ometron VQ-400-A-F ke roda gigi.

3. Putaran motor yang di ubah dengan inverter.

4. Getaran pada roda gigi lurus. 


\section{HASIL DAN PEMBAHASAN}

\subsection{Hubungan Putaran Dengan getaran torsional roda gigi}

Hubungan putaran terhadap getaran torsional dapat dilihat pada gambar 4.3 berikut ini .

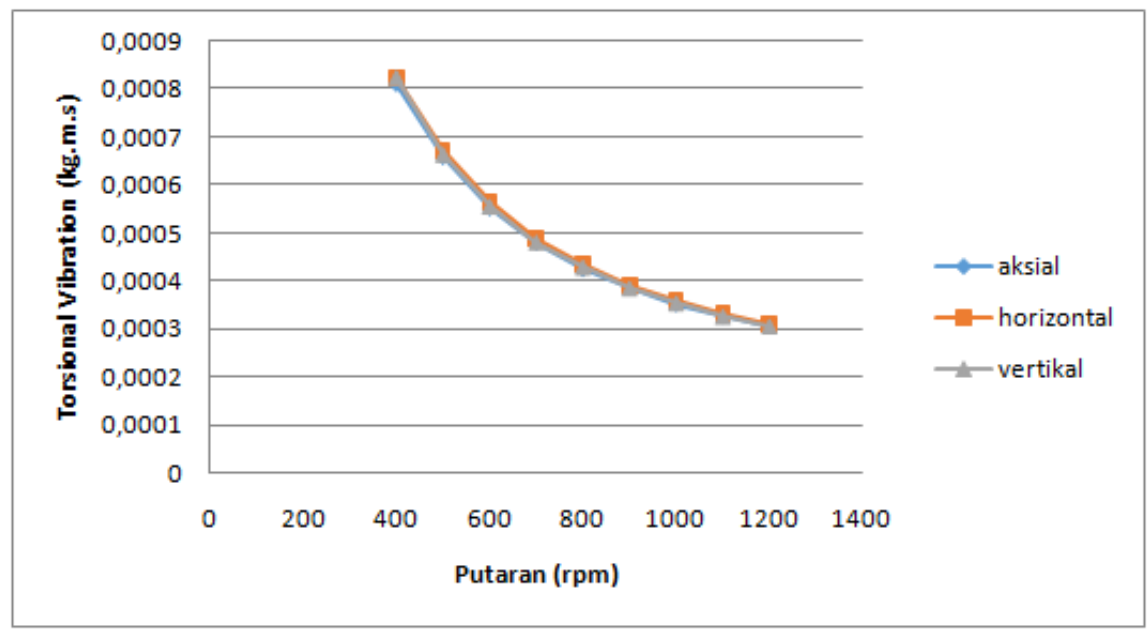

Gambar 4.1. Torsional vibration vs rpm pada roda gigi normal

Jika dilihat dari grafik 4.1. di atas maka dapat disimpulkan bahwa kecepatan putaran mesin mempengaruhi getaran torsional yang terjadi. Semakin besar kecepatan putaran pada mesin maka getaran torsionalnya akan semakain kecil.

\section{KESIMPULAN DAN SARAN}

\subsection{Kesimpulan}

Hasil penelitian menunjukan bahwa nilai getaran torsional pada kecepatan $400 \mathrm{rpm}$ sebesar 0,000822726 kg.m.s dan getaran torsional pada putaran $1200 \mathrm{rpm}$ sebesar 0,000307676 kg.m.s, dapat disimpulkan bahwa semakin besar kecepatan putaran pada mesin maka semakin kecil getaran torsional yang dihasilkan.

\subsection{Saran}

Untuk pengembangan lebih lanjut dalam penelitian selanjutnya, maka dapat disampaikan saran-saran sebagai berikut:

- Penelitian selanjutnya gunakan alat uji khusus untuk vibration torsional.

- Penelitian selanjutnya menggunakan variasi kekentalan pelumas untuk mengurangi getarannya.

\section{DAFTAR PUSTAKA}

[1].Timothy R. Griffin "Computer-Aided Design Software for Torsional Analysis" Mechanical Engineering Faculty of the Virginia Polytechnic Institute and State University. Blacksburg, Virginia. March 5, 1998. 
[2].Scheffer, C. dan Girdhar P. Practical Machinery Vibration Analysis and Predictive Maintenance. Netherlands, IDC Technologies. 2004.

[3].Spotts M. F, "Design Of Machine Elements" Fifth Edition, Mechanical Engineering Departement The Technological Institute Northwestern niversity 